v. 13, n.3

Vitória-ES, May.-Jun. 2016

p. 26 - 47 ISSN 1808-2386 DOI: http://dx.doi.org/10.15728/bbr.2016.13.3.2

\title{
The Theory of Practice and the Development of Ambidexterity in Software Innovation Process
}

\author{
Adriano Olímpio Tonelli ${ }^{\dagger}$ \\ André Luiz Zambalde ${ }^{\Omega}$ \\ Universidade Federal de Lavras - UFLA \\ Mozar José de Brito \\ Universidade Federal de Lavras - UFLA \\ Paulo Henrique de Souza Bermejo ${ }^{ \pm}$ \\ Ministério da Educação - MEC
}

Instituto Federal de Educação, Ciência de Tecnologia de Minas Gerais

\begin{abstract}
This study aims to point out and analyze, from the perspective of practice theory, the process in which ambidexterity are formed within the innovation process, considering the mutual constitution between local actions and institutional logics. Qualitative data were collected from a longitudinal approach throughout the development of an innovative software solution for the mining industry. The results show that process of becoming ambidextrous is based on three stages that reflect the relationships between logics and actions: generation of initial conflicts, reaction to conflicts and stabilization via logic-action dynamics.
\end{abstract}

Keywords: Innovation. Practice theory. Ambidexterity.

*Author for correspondence:

$\dagger$ Master in Business Admnistration by the Federal University of Lavras - UFLA. Link: Federal Institute of

Education, Science

Technology of Minas Gerais, Formiga Campus.

Address: Federal Institute

Minas Gerais - Campus Ant

Rua Padre Alberico, \#

440/Rua São Luiz Gonzaga

SN, Formiga - MG - Brazil.

CEP 35570-000.

E-mail:

adriano.tonelli@ifmg.edu.br

Phone: (35) 984322114
$\Omega$ Doctor in Systems $¥$ Doctor in Business Engineering and Administration by the Computer Science. University of Sao Paulo Federal University of Rio de Janeiro - UFRJ Link: Department of Computer Science, Federal University of Lavras - UFLA. Address: Campus Center - Lavras - MG Brazil.

CEP 37200-000.

Caixa- postal: 3037 .

E-mail:

zamba@dcc.ufla.br Phone: (35) 38291534 USP

Link: Departament of Administration and Economy, University Federal of Lavras UFLA.

Adress: Campus Universitário - Lavras MG - Brazil. CEP 37200-000. Caixa-postal: 37 . E-mail: mozarjdb@ufla.br Phone: (35) 38291475 \pm Doctor of Engeenering of Knowledge Management. Federal University of Santa Catarina. Link: Ministry of Education, Ministry of Education.

Address: Ministry of Education, Executive Secretariat. Ministry of Education Civic Administrative Zone Brasília - DF - Brazil. CEP 70047-900.

E - mail: bermejo@dcc.ufla.br Phone: (61) 20227856

Note from the Editor: This paper was accepted by Bruno Felix. 


\section{INTRODUCTION}

$\mathrm{n}$ the software industry, new technologies frequently arise making current technologies obsolete and creating opportunities for firms to develop new products and services (LYYTINEN; NEWMAN, 2008; LYYTINEN; ROSE, 2003). It is therefore essential that software companies are able to assimilate the technological development of the sector as well as the latent demands of customers and users in order to develop

innovative solutions that create new markets and/or exceed competing solutions.

The ability to generate innovations must, however, be aligned to an operational capability to explore efficiently the current companies' portfolio solutions (AUH; MENGUC, 2005; JANSEN; VAN DEN BOSCH, VOLBERDA, 2005). Essentially, we need to encourage firms to promote ambidexterity (TUSHMAN; O'REILLY, 1996), and the ability to balance capabilities that, in most cases, prove to be conflicting: (1) flexibility, fault tolerance and experimentation to foster developing innovative solutions that will generate returns in the future (ROPER; DU; LOVE, 2008; TEECE, 1986) and (2) control to ensure the efficient delivery of products and services that currently support the firm (LAVIE; KANG; ROSENKOPF 2011; NAPIER; MATHIASSEN; ROBEYD, 2011;. TUSHMAN; O'REILLY, 1996)

The construction of the ambidextrous ability is influenced by a cultural sphere that involves the values, principles and working standards consolidated over time in companies (O'REILLY, TUSHMAN, 2007; RAISCH; BIRKINSHAW, 2008; TUSHMAN; O'REILLY, 1996). Such influence especially occurs in firms that are comatose due to excessive focus on current operations (RAISCH; BIRKINSHAW, 2008; TUSHMAN; O'REILLY, 1996). As the need to innovate arises, due to economic crisis, new technologies or changes in the market, we need to create an environment permeated by new values (that reinforce openness, fault tolerance, creativity and flexibility), conducive to generating innovation and distinct from the consolidated set of values that reinforce efficiency, strict adherence to deadlines, control and standardization (LAVIE; KANG; ROSENKOPF, 2011; NAPIER; MATHIASSEN; ROBEYD, 2011).

Although the influence of cultural aspects of the company on the construction of ambidexterity has been discussed in representative studies on the subject (O'REILLY, TUSHMAN, 2007; RAISCH; BIRKINSHAW, 2008; TUSHMAN; O'REILLY, 1996), some gaps remain. There is a lack of studies that address the process of building ambidexterity from interactions of elements of different organizational levels. Even though studies have 
contributed to the understanding of influences of micro aspects (eg, top management position) and macro (for example, competitive dynamics) (LUBATKIN ET AL, 2006; RAISCH; BIRKINSHAW, 2008) to reach the ambidexterity, interactions between actions located at the micro level and aspects of organizational culture are not yet exploited (LAVIE; KANG; ROSENKOPF, 2011; RAISCH; BIRKINSHAW, 2008).

Thus, the question arises: how do relationships between actions and logic present in the company's culture, shape the emergence of ambidexterity within the software innovation process?

To answer the question, this study applies the practice perspective (GIDDENS, 1984; JARZABKOWSKI, 2008; ORLIKOWSKI, 2007; WHITTINGTON, 2006) to analyze the ambidexterity formation process in a company in the software industry that is in a period of change: a context of excessive focus on the use of current capabilities to a context shift toward innovation.

The study is based on the central argument that both the contextual aspects related to the organizational culture and the local actions (micro level) are relevant to the construction of ambidexterity. Therefore, it is necessary to build an approach based on the practice perspective, consider dualities between these two levels.

\section{AMBIDEXTERITY FUNDAMENTALS}

The concept of ambidextrous organization (TUSHMAN; O'REILLY, 1996) refers to the capacity of organizations to compete in mature markets and developing new products and services for emerging markets. While the first strategy requires efficiency of operations and costs, the second is based on a considerable demand of experimentation and flexibility. In principle, organizations able to perform simultaneously both strategies are more efficient than organizations that favored one over the other (HE; WONG, 2004).

In software companies, the concept of ambidexterity is a very fertile field for study. The environment of these companies is often characterized by choices between conflicting options (NAPIER; MATHIASSEN; ROBEYD, 2011). Within a competitive industry, characterized by large demands for innovation and learning of new technologies to ensure survival (LI; SHANG; SLAUGHTER, 2010), different simultaneous approaches are needed: i) optimizing current development processes and at the same time adapting such procedures to deal with customers changing needs through projects; ii) to take advantage of existing capabilities in terms of technology and customer base and at the same time, explore new technological 
opportunities and new market niches (NAPIER; MATHIASSEN; ROBEYD, 2011).; iii) to promote the consolidation of current processes and simultaneously absorb new concepts and development models to address new base technologies (LYYTINEN; ROSE, 2003).

The balance between conflicting strategies is, however, a challenge for companies (LAVIE; KANG; ROSENKOPF, 2011; NAPIER; MATHIASSEN; ROBEYD, 2011; SIREN; KOHTAMAKI; KUCKERTZ, 2012),

Different actions can be taken to reach the ambidexterity. Two main approaches are highlighted: i) temporal separation, engaging in exploration activities and in exploitation of current capabilities in different periods; ii) structural separation, concentrating exploitation and exploration activities in the same period, but in different units (GIBSON; BIRKINSHAW, 2004; RAISCH; BIRKINSHAW, 2008).

However more recent contributions have pointed to other strategies. La Vie et al. (2011) propose a classification scheme based on choices about exploration and exploitation in two areas: i) structure (alliance for exploration with new partners vs. alliances to take advantage of existing partnerships) and ii) function (alliances for research and development vs. alliances for the production and marketing). Thus, they found that, to overcome balancing challenges, companies could explore in a domain and seize another. For example, companies can form alliances R\&D (exploration) with existing partners (exploitation) (LAVIE; KANG; ROSENKOPF, 2011). Napier et al. (2011) focused on the creation of contextual ambidexterity, contemplating how companies create environments that enable people to make judgments about conflicting demands and to balance innovation and the use of existing capabilities within the same unit.

For these different actions in pursuit of ambidexterity, the cultural aspects of the company have a central role. Tushman and O'Reilly (1996) argue that management's ability to build a proper culture is the key requirement for achieving structural ambidexterity. In addition, reconciliation between different cultures (innovation and use) is essential to the success of companies (VINEKAR; SLINKMAN; NERURS, 2006).

The influence of the set of rules, principles, values and standards in the consolidated company happens especially when considering the dynamics of the evolution of organizations, described by Tushman and O'Reilly (1996). As the organization grows around a portfolio of products and/or services, structures and systems are consolidated to ensure that production is conducted efficiently. 
However, faced with the need to innovate, due to several factors such as customer pressures, technological changes, new regulations or economic crises, firms need to create mechanisms based on norms and values (e.g., fault tolerance, creativity and flexibility) distinct from those consolidated long ago (e.g. efficiency, strict adherence to deadlines, control and standardization) (TUSHMAN; O'REILLY, 1996; VINEKAR; SLINKMAN; NERURS, 2006). In essence, we need to build a new set of values that can guide the work of employees to the balance between innovation and exploitation.

Although the influence of cultural aspects of the company on the construction of ambidexterity has been treated in representative studies on the subject (RAISCH; BIRKINSHAW, 2008; TUSHMAN; O'REILLY, 1996; VINEKAR; SLINKMAN; NERURS, 2006), it is still necessary to promote investigations that consider how the actions to create ambidexterity interact with aspects of the environment and the organization, including culture (LAVIE; KANG; ROSENKOPF, 2011; RAISCH; BIRKINSHAW, 2008). It is necessary to explore interactions between factors coming from different organizational levels, such as localized and actions conducted on the company's daily routine and the set of values and norms consolidated in organizational culture (RAISCH; BIRKINSHAW, 2008).

Facing the need to clarify interactions between actions and contextual factors, the following section presents the fundamentals of practice theory, theoretical apparatus used as a reference in this work for the investigation of interactions between actions and organizational logics for the ambidexterity's formation.

\section{PRACTICE THEORY FUNDAMENTALS AND THE CONSTRUCTION OF AMBIDEXTERITY}

The theory of practice, widespread by the works of Anthony Giddens, Pierre Bourdieu, Wittgenstein and others, is a broad theoretical approach that is based on the duality between action and structure (JARZABKOWSKI, 2008; ORLIKOWSKI, 2007; WHITTINGTON, 2006). From the perspective of practice in human action, there are macrostructures that, in turn, are influenced by the actions of people (GIDDENS, 1984). It is therefore an approach that rejects dualism and reinforces a relational ontology, which exerted influence on different areas relevant to studies on technology and organizations.

Given this focus on the duality between agency and structure, the theory of practice has given contributions in different approaches to organizational studies. In particular, recent studies (BATTILANA, DORADO, 2010; BINDER, 2007; LOK; DE ROND, 2012; SMETS, 
MORRIS, GREENWOOD, 2012) have shown strong influences of the practice theory on institutional theory and on aspects related to culture in organizations.

Under the focus of practice, institutions, norms and values can be defined as standards for social practices that: i) are distributed over time and space; ii) are routinized in the environment and iii) are legitimized in terms of a logic that classifies what is acceptable and what is not. In this sense, these macrostructures (ie, institutions, norms and values) take the form of scripts that represent shared understandings and influence the actions of daily routine (BINDER, 2007; SMETS, MORRIS, GREENWOOD, 2012). These actions, taken on a continuous basis by people, can play or modify the structures, maintaining a dual relation (FELDMAN; ORLIKOWSKI, 2011; GIDDENS, 1984) and serving as apparatus to explain different phenomena from relations between actions at the micro level and structures at the macro level (JARZABKOWSKI, 2008).

The articulation between the perspective of practice and ambidexterity is based, first, on the pattern of organizational evolution proposed by Tushman and O'Reilly (1996), as discussed in section 2. Given this pattern, two points can be highlighted.

First, as emphasized in the ambidexterity literature (RAISCH; BIRKINSHAW, 2008; TUSHMAN; O'Reilly, 1996), long periods of concentration in the use of existing capabilities can generate an inertia within organizations and the consequent inability to generate the innovations reinvigorate business and create new markets. Under the focus of practice this inertia can be built as logic associated with the efficiency, control and standardization are reinforced over time in daily actions (ORLIKOWSKI, 2007; WHITTINGTON, 2006). This create, therefore, practical insights shared in the company, which encourage acceptable behavior (e.g. standardization activities, low fault tolerance and agility) and reject alternative behaviors (e.g., testing, fault tolerance, creativity) (JARZABKOWSKI, 2008; SCHATZKI, 1996).

Second, in situations of change, companies need to innovate to stay on the market (LAVIE; KANG; ROSENKOPF, 2011; NAPIER; MATHIASSEN; ROBEYD, 2011; TUSHMAN; O'REILLY, 1996). It is in this context that the modification of previously consolidated organizational logic is required from actions and interactions that occur in dayto-day business (SMETS, MORRIS, GREENWOOD, 2012; WHITTINGTON，2006). New logic must be created and consolidated from the daily actions at the same time, to some extent, previously consolidated logic is kept in order to maintain the regular procedures to ensure revenue in the short term. This change, in turn, is given from actions that run on a 
continuous basis, reinforce new distinct logics and create a new cultural environment in the company (JARZABKOWSKI, 2008; SMETS, MORRIS, GREENWOOD, 2012).

Therefore, the practice perspective of the application as a theoretical approach provides the inclusion of the organizational context, especially the culture of the company, considering it together with the actions conducted on a daily routine which may restrict or provide building ambidextrous skills.

\section{METHODOLOGY}

It is proposed to conduct a qualitative research of a longitudinal sectional and based on case study (EISENHARDT, 1989), to provide theoretical validity (KIRK; MILLER, 1986). The qualitative approach choice is justified to the extent that it seeks to emphasize the interpretive aspects of engaged actors in the researched context, aligning the research procedures to the theoretical assumptions of the practice perspective, where interpretation, values and norms shared by the actors in social context are a central aspect of the research (FELDMAN; ORLIKOWSKI, 2011; GIDDENS, 1984). From the use of the longitudinal section, we seek to identify and analyze the actions and organizational logics over time. Inasmuch as according to the practice tradition (GIDDENS, 1984; WHITTINGTON, 2006), localized actions performed over time reinforce or modify structures, it is thought that the longitudinal section shown is suitable for the alignment between methodology and theoretical approach used in this work.

The case studied comprises a company from the software industry. To preserve confidentiality, innovation developed and the company will be handled respectively by fictitious names Beta Platform and Beta Company. The case selection is based on the following criteria: (i) the selected company went through a long period of stability followed by a period of rupture; (ii) in the period of rupture, the organization sough to balance innovation development (new product development) and the conduction of traditional operations (based on current product portfolio). These two criteria make the trajectory of the company Beta aligns with the organizational process of evolution characterized by Tushman and O'Reilly (1996), being a suitable case to study the ambidexterity formation process.

Data were collected from two different sources: semi-structured interviews and nonparticipant observation, in order to provide triangulation of data sources.

Non-participant observation. The non-participant observation was conducted by three researchers from September 2011 to April 2012. These observations were made in meetings 
conducted by senior management and within the business development units. 20 visits were made to the company, with an average duration of four hours each. From the observation, detailed information can be captured about how work is really driven by people within the organization (WHITTINGTON, 2006).

Interviews. 11 interviews were conducted with employees who work in different fronts in the company (Table 1) in order to provide a blend of different views. The interviews were conducted individually at the company's premises and took an average of 50 minutes. All interviews were recorded and later transcribed. Table 1 illustrates the relationship of the interviewed actors.

The interview script was developed from the initial observations made in the company. Additionally, in order to align themselves with the fundamentals of the practice theory, the script was based on three basic categories: (i) aspects of organizational culture; (ii) the actions taken on the day-to-day business for both projects and to develop new products and (iii) the relationship between actions and cultural aspects.

For the identification of agents to be interviewed, two sampling strategies were employed within organizations: for convenience and snowball. In the first case, the strategy followed the interest and availability of social actors to participate in it; in the second, they sought to statements made by actors who participated (MALHOTRA; BIRKS, 2007).

\begin{tabular}{|l|c|l|}
\hline \multirow{2}{*}{ Interviewee } & Date & Main attributions within the innovation process \\
\hline \multirow{2}{*}{ CEO } & $11 / 26 / 2011$ & \multirow{2}{*}{ Development of strategies for innovation } \\
\cline { 2 - 2 } & $03 / 14 / 2011$ & \\
\hline \multirow{3}{*}{ Director of Innovation } & $11 / 29 / 2011$ & \multirow{2}{*}{ Portfolio management of innovation initiatives } \\
\cline { 2 - 2 } & $04 / 18 / 2012$ & \\
\cline { 2 - 2 } & $11 / 04 / 2012$ & \\
\hline \multirow{2}{*}{ Product Manager } & $03 / 21 / 2012$ & Creation of vision for new product portfolio; Development of \\
\cline { 2 - 2 } & $04 / 25 / 2012$ & new products; Organization of new ideas \\
\hline \multirow{2}{*}{ Development Manager } & $04 / 24 / 2012$ & Technical development; Team management. Outsourcing \\
\cline { 2 - 3 } & $11 / 07 / 2012$ & contracts \\
\hline Developer I & $04 / 13 / 2012$ & Specification of requirements and coding \\
\hline Developer II & $03 / 20 / 2012$ & Specification of requirements and coding \\
\hline
\end{tabular}

Table 1 - List of interviewed agents

Source: Elaborated by the authors 
From the triangulation between the two sources, we sought to promote reliability and validity of the findings (LINCOLN; GUBA, 1985). Thus, data from one source can be confirmed from other sources.

Initially, observations were conducted in the company, from the participation in senior management meetings and two workshops for socialization lessons learned. From the observations, an interview was made with the CEO. After this first interview, the data collection process was conducted from an iterative approach (EISENHARDT, 1989). In every initiative of collecting data from a source, interview or observation, data were analyzed and new demands for breakdowns and confirmations that come from other sources were identified for the implementation of a new collection cycle.

The following steps were conducted for the analysis of data at each iteration:

Step 1. Construction from interviews, observations and document analysis, of the temporal sequence of events and actions in order to reconstruct the trajectory as well as the shares of the company over time (CORBETT-ETCJEVERS, 2011).

Step 2. Identification, from the narrated sequence of events, of the actions that demonstrated continuously both current capacity utilization context (exploitation) and in the context of innovation created in the company. This identification aims to capture the local actions, considering what people do in practice (WHITTINGTON, 2006).

Step 3. Analysis of continued actions from the mapping of these in relation to cultural aspects of the organization. This mapping is aligned with the idea of constitutive relations between agency and structure, as proposed by the theory of practice (FELDMAN; ORLIKOWSKI, 2011; GIDDENS, 1984; WHITTINGTON, 2006).

\section{RESULTS}

\subsection{BETA COMPANY: FROM INERTIA TO CHANGE}

Beta Company was founded in the early 2000s based on a solution for optimization for the mining sector. Since its foundation, the company passed, until 2010, for a period of considerable growth and is among the leaders in the Brazilian market software solutions for optimization of mining operations. During this period, the organization offered a solution that was configured as a set of modules, each applicable to specific processes within the mine. Thus, the company's business revolved around the delivery of this product to customers, made from customizations projects requested by each customer. These customizations were the major source of improvement for the product. Adjustments requested by customers were 
incorporated and made the product evolve incrementally. Driven by growth, posture focused on efficient delivery of the main product has established itself over the years in the Beta Company.

However, with the economic crisis that began in 2008, the demand for customization projects for customers had considerably reduced. According to the CEO of Beta Company:

"With the crisis, companies operating in the mining sector began to cut costs and investments, resulting in a significant reduction in demand for projects for our company."

The reduction in demand for projects, along with the emergence of competing solutions, fired a number of changes in the Beta Company. In essence, these changes are associated with the development of a new solution that would be technologically updated and acted in a different line of mineral production chain, in which competitors have not worked: automation and real-time management of mineral production chain.

The new solution, Beta Platform, comprises three main layers: (1) an open platform to enable integration with other solutions already used in mining; (2) a set of applications that, running on the open platform, focus on automation of various operations in the mine and (3) a Standard Development Kit (SDK) that allows third parties to develop new applications in the platform.

With the development of Beta platform, the company moves away from its current products and technologies. According to the Director of Innovation:

"In the area of automation and mine management, this solution is new, especially when considering the use of open platforms that allow integration with legacy systems and the use of temporal databases that can generate and analyze data in real time. "

With the flourishing innovation initiative, Beta faced challenges in promoting conciliation between conflicting instances involved in the construction of ambidexterity: (i) the already consolidated operations of customization and delivery of the main product, albeit with reduced demand, continued to be the main source of revenue and (ii) the new Beta Platform development initiative in order to ensure competitive advantage long term for the Beta Company.

\subsection{INTERACTIONS BETWEEN ACTIONS AND LOGICS FOR THE CONSTRUCTION OF AMBIDEXTERITY}

From the data collected in the Beta Company and under the practice perspective approach, it is observed that the construction of ambidexterity took place from three stages 
that describe interactions between organizational actions and logic in order to promote the construction of ambidextrous capacities in the Company.

\subsubsection{Stage 1: Creation of Initial Conflicts}

Facing the crisis that started in 2008 and the advance of competing solutions, two key decisions were taken by the top management of Beta Company: direct efforts for the development of innovation and reduction in headcount. These two decisions, however, provoked conflicts with logic previously consolidated in the Company. Such conflicts occur to the extent that the actions refer to logics that are contrary to what was previously consolidated in the Company (JARZABKOWSKI, 2008; SMETS; MORRIS; GREENWOOD, 2012).

\section{Conflict 1: Approaches for projects and approaches for new products}

Over time, Beta Company consolidated a vision focused on the efficient conduction of customization projects of the main solution. This vision guided for ages the way the Company works. According to Developer I:

[The Company had] "a very focused vision on projects, scope, time, budget and welldefined features, and a more rigid posture to meet deadlines with clients."

The approach aimed at consolidated projects in Beta Company is shown, however, opposed to a favorable environment to the development of new products. According to the CEO of the Company:

"Products have to be designed carefully to the market, to be killers, to consolidate the company's position and overcome competitors (...) Projects [instead] are conducted to meet the specific needs of the clients who hire the solution. This is to meet the scope and deliver on time. The good project manager is therefore the one who has an urge to deliver the project within what was specified. In relation to the product, we have to consider creativity and other features that are not central to project management."

The CEO's statement illustrates the conflicts between work related to development projects and the development of new products. While the first is linked to a logic in which pressures deadlines and strict controls privilege faster solutions (NEWELL et al., 2009), the second is associated with a work logic that emphasizes flexibility, creativity, fault tolerance and suitability in the long run (NEWELL et al, 2009;. ROPER; DU; LOVE, 2008; TEECE, 1986). In addition, contrary to what occurs in the projects, the development of new solutions, 
sometimes appears as an initiative not initially linked to clients or direct sale, permeated with great risk of not getting consistent results.

\section{Conflict 2: Internalization and downsizing}

Traditionally, the Beta Company adopts a posture of internalization of development and project delivery to clients. According to the Development Manager:

"We always use internal resources to develop our projects. Increases in demand always involved increasing in staff. So, hiring and organic growth of the company were the consequences of the increased demand for our solution in the mining market."

However, the crisis that began in 2008 forced the Board to adopt a posture to reduce staff, which leads to a distinct logic in terms of internal structure and growth in the Beta Company. The reduction in demand for projects resulted in a need to reduce the workforce and maintain a leaner structure. According to the Director of Innovation:

"With the crisis, we had to greatly reduce our workforce, something we had not experienced before. With the recovery of the market, this decision also provided the emergence of a new vision that we could grow and get deliverability without necessarily grow organically."

Thus, a new logic of downsizing is consolidated in the Company, inclined to seek greater scalability without the need for organic growth.

\subsubsection{Stage 2: Reaction to Conflicts}

The experience of agents facing competing logics triggers a reflexivity in the context of the action (BATTILANA; DORADO, 2010; GIDDENS, 1984). In this sense, the employees seek actions that can cope with the conflicts between established and emerging logics in the company.

Based on these results, it can be observed actions in the context of the organizational structure, development process and external relationships.

\section{Organizational structures: the creation of structural ambidexterity}

Facing the conflict between logics to develop new products and logic oriented projects, Beta Company adopted a strategy to promote structural separation (RAISCH; BIRKINSHAW, 2008; TUSHMAN; O'REILLY, 1996), with a dedicated unit to maintain regular operations and focusing on projects (project Board) and another dedicated to the development of the Beta Platform (Innovation Management). According to the CEO: 
"This separation was made as it was necessary to build a wall that separated two distinct visions. The dedicated staff to projects should have a canine faithfulness to deadlines, scope and defined budgets. But the products of staff should have more flexibility and creativity, having no activities too tied to deadlines or scope. If we do not separate these two views, project teams, having a more rigid stance, end with initiatives for new products."

From the creation of the Innovation Board, independent of the Project Board, it was possible to create, gradually, a more favorable attitude to the uncertainties and experimentation demands that the development of innovation requires. In this situation, according to the Director of Innovation:

"Put out the fire on projects for clients always end up being priority. The creation of the Innovation Board allowed us to have proper focus to the development of new products, we develop different approaches what had been traditionally practiced in the company. We have a little rigid structure, we avoid to draw hierarchies to give an active voice to all within the processes of design and development of solutions."

The separation of areas dedicated to projects and product was a fundamental action, through which the Beta Platform development practices took place. Development processes and approaches to maintaining external relationships were built in order to complete the creation of an environment conducive to the creation of new solutions.

\section{Development processes: contextual ambidexterity}

In the development process, given the need to consolidate the Company Beta logic that would provide greater flexibility, creativity and experimentation, development actions were based initially in a detachment from traditional project management processes that had been established long ago in organization. According to the Director of Innovation:

"At first, we prefer to create a very open approach to avoid drawing hierarchies. We wanted to create an environment that would encourage experimentation and creativity, giving autonomy to the people involved."

In the early stages, it emerged in the Company a development approach that rejects projects logic (NEWELL et al., 2009) and goes close to receptive logics to the emergence of innovations, such as fault tolerance, fostering experimentation, opening participation (ROPER; DU; LOVE, 2008; TEECE, 1986). 
However, an excessive focus on creativity made that the Platform development initiative did not present significant progress in terms of partial versions and the new solution in development prototypes. According to Director of Product:

"Over time, we realized that ideas arise all the time and in large volume, with this, the team could not effectively focus on developing ideas and creating partial platform versions. At some point, we have to break the flow of ideas and focus on development."

Therefore, with negative results arising from an excessive focus on creativity, there was a movement of the agents towards the consolidation of an organization's work in iterations and the incorporation of a form of work that addressed some discipline to meet deadlines with deliveries and partial validations.

According to Developer I:

"Each iteration is comprised of a design phase and one development. In the design phase, we capture the ideas and prioritize in a backlog. After closing of this cycle, we set off for development, where the flow of ideas is blocked and considered only in the next iteration. Finalized development, we entered a prototype that is presented to our existing clients, board and staff to support the next iteration.

"So, before conflicts between logical that encourage creativity experimentation (i.e. new products) and logics that encourage discipline and agility in the results of appearance (i.e. projects), it creates a contextual ambidexterity (GIBSON; BIRKINSHAW, 2004) within the development, balancing creativity in the design phase and discipline at the close of backlog and conducting development activities. The new scenarios that provided ambidexterity in the development process was, in turn, constructed from a synthesis of the negative experiences by employees in an attempt to implement a radical change and past experiences related to project management.

\section{External relationships}

Two types of relationships were identified and maintained over the Beta platform development process: (i) relationships with customers and (ii) relationships with the company for outsourcing development activities.

In regard to client relationships, there was a longstanding relationship exploitation with clients to absorb external and knowledge and strengthening a logic conductive to product innovations. 
Early in the development of the Beta platform, the organization had a portfolio of important clients, being among the largest in the national market. Thus, according to the Development Manager:

"As we had frequent visits to technical and sales teams on our clients, it was natural to follow a path of relationship with them for automation of knowledge contribution in the context of optimization and new demands for mobile asset management within the mines."

Partnerships with customers were signed because, according to the Development Manager:

"As there was plenty of uncertainty and lack of knowledge about the scope and solution requirements, two of our customers especially contributed regarding the platform's usability issues, expected functions of the product within the mineral production chain and automation mechanisms defendants in a mine."

Relationships with other software companies were also maintained in order to outsource part of the Beta platform development work, the Company has a backing to downsizing of logic and a production-based approach on projects.

According to the Development Manager:

"At first, we thought it would be possible to develop everything internally. However, this was not possible. We could not meet the initial deadlines to present prototypes to our customers. To start such project is very hard work, and with the team we had internally available, we could not proceed as expected. "

Given the difficulties in moving forward with the development of Beta Platform and downsizing logic in consolidation in the Company, the solution found to increase development capacity was outsourcing.

The outsourcing approach developed in Beta Organization, however, is conducted under a strict approach focused on projects. According to the Director of Innovation:

"We take a project approach, specify the scope and term and launch on the market (...) optimization algorithms and other business rules are not passed to external development."

So from the data collected, one can identify the relationship actions with external agents expressed from syntheses between different logics (projects x new product and internalization $\mathrm{x}$ downsizing): outsourcing to exploitation capabilities (exploitation) and relationships with customers to create new knowledge for the organization and for the mining sector. 
Relationships with current clients seek to strengthen the market built by the Company over the years and at the same time, are associated with the creation of new knowledge to the development of innovations. Outsourcing practices seek to strengthen an old logic of projects and efficiency, simultaneously, reinforcing a new logic that refers to organizational and leaner team structures.

\subsubsection{Stage 3: Stabilization via Dynamics Between Logics and Actions}

In the Beta Company, actions related to organizational structure, process development and external relationships were fired in response to conflicts between established and emerging logics. These ongoing actions created syntheses between conflicting logics. In such syntheses processes, three dynamics were found:

Dynamic 1: Balance between logics via destabilization of previous logic and structural separation. The weakening, due to economic crisis, of the logic of projects that supports the achievement of the Company's revenue favored the formation of an ambidexterity in terms of organizational structure. This dynamic is consistent with the pattern of organizational evolution described by Tushman and O'Reilly (1996). What Tushman and O-Reilly (1996) also point out it is that many organizations become unable to promote changes towards the generation of innovations, becoming victims of past success. The structural separation (RAISCH; BIRKINSHAW, 2008) promoted by the Beta Company was possible due to the weakening of a logic dedicated to designs and aimed to give effective balance with a new logic oriented to innovations. Thus, the creation of units dedicated to innovation (Innovation Management) and projects (Project Board) was implemented for separation initiatives and reduction of the propensity of an overlap to one another in the competition for resources.

Dynamic 2: Redemption of previous logic for balance with new logics. In the formation of the Beta platform development process, the non-appearance of the results in actions by the emerging logic of flexibility and experimentation triggered the need to restore, within the innovation process, a project logic that was already established in the Company. Therefore, the inefficiency of an emerging logic demanded the rescue to another consolidated concurrent logic previously, to create a balance in terms of development processes.

This dynamic describes the formation of a contextual ambidexterity (GIBSON; BIRKINSHAW, 2004) in the development process. The actions within the development process (e.g. iterative approach to development, separation of iterations: stage of generating 
ideas and development stage) promoted a balance between the emerging concept focused on new products and the old logic focused on projects.

Dynamic 3: Balance and crossing: old logics for new knowledge, new logic for exploitation of capabilities. This dynamic describes the relationship between: (i) actions to outsourcing and conflicts between internalization and downsizing and (ii) customer relationships and conflicts between logic related to projects and new products. From outsourcing, the logic associated with downsizing and projects have been strengthened. As from the customer relationships, the company maintained a focus on current customer base, reinforcing a consolidated logic. However, these relationships were fired by a new logic focused on experimentation and creativity for new development solutions. The balance feature of this dynamic occurs because of both old and emerging logical balancing actions. In addition, the crossing characteristic is given based in what was described by Lavie et al. (2011) to reach ambidextrous relationships: exploration from current relationships and capabilities in conciliation with the benefit from new partnerships. In the Company studied, there was the presence of partnerships with existing customers to generate new knowledge about the application of automation solutions for mining. At the same time, the practice of outsourcing with new partners was used to achieve efficiency in the development process.

\section{ANALYTICAL SYNTHESES: AMBIDEXTERITY FORMATION FROM THE PERSPECTIVE OF PRACTICE}

Based on the Beta Company study and considering an approach based on practice, one can note three stages that reflect relationships between logic and actions and describe the ambidexterity building process in the organization studied (Figure 1).

The Beta Company went through a long period of inertia (TUSHMAN; O'REILLY, 1996), characterized by constant reinforcement in practices that provide efficient delivery of projects based in the main suite of Beta Company. During this period, consolidated organizational logic, to the extent that represented the shared knowledge on how to conduct the activities in the Company, guided the actions of employees (JARZABKOWSKI, 2008; WHITTINGTON, 2006). 


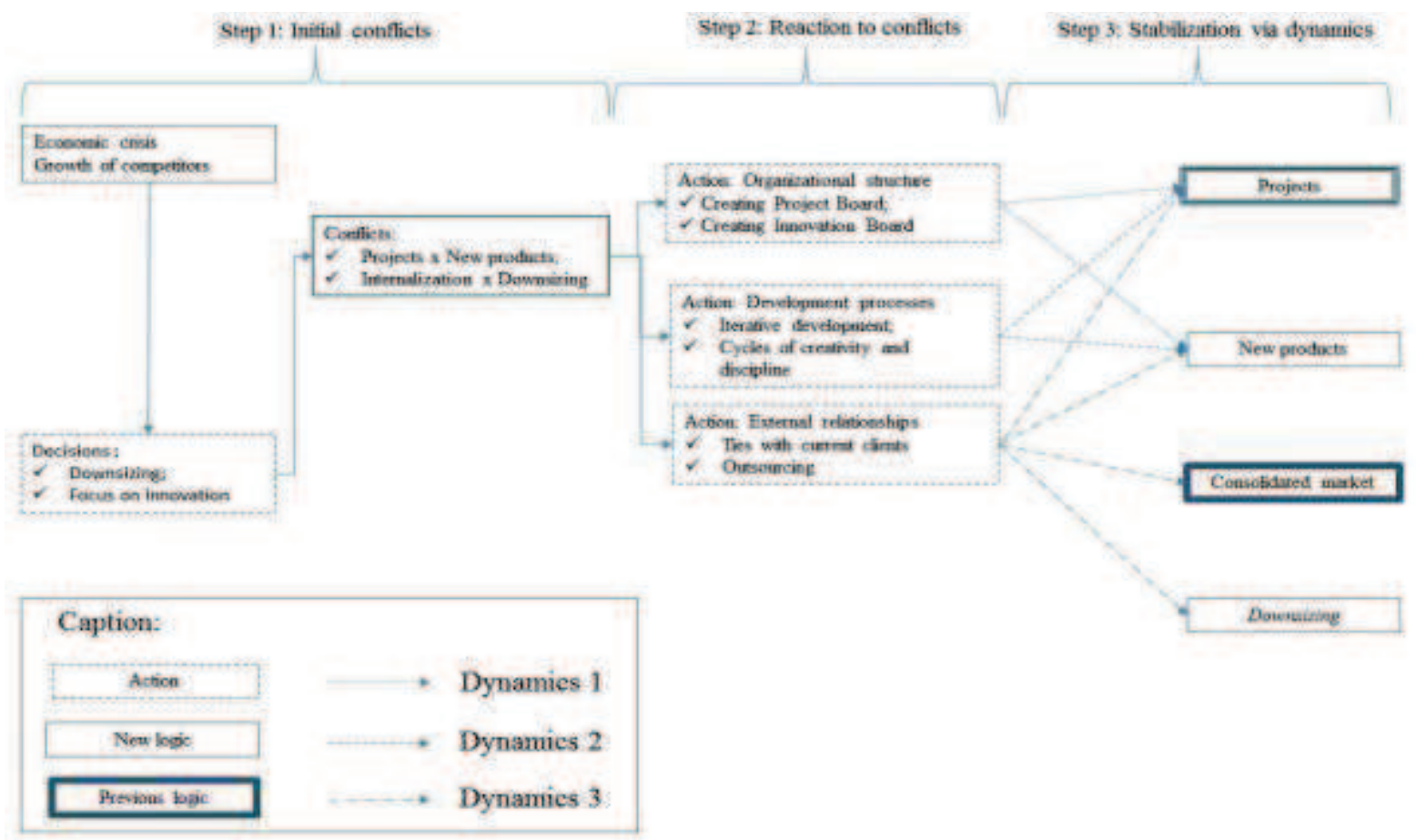

Figure 1 - Synthesis of the construction of ambidexterity Source: Elaborated by the authors

However, two events occurred in the environment, an economic crisis and the progress of competitors, cause two decisions by the board: downsizing and focus on innovation. These decisions cause a clash with organizational logics (aimed at projects and internalization) consolidated long ago in the Company. In the first stage (Creation of initial conflicts), a challenge to the prevailing logic in the Organization - actions taken in day-to-day business, if strengthened over time, can subvert established logic and instantiate new approaches (GIDDENS, 1984; JARZABKOWSKI, 2008; WHITTINGTON, 2006). It is therefore the first step in the construction of ambidextrous capabilities to provide a focus on the Company's innovation.

In order to strengthen the two decisions taken by senior management and deal with conflicts generated by these decisions, new actions within the organizational structures, process development and external relations are conducted. This second stage (reaction to conflict) is characterized by driving actions directed to give effective support to the change in the Company.

Repeated over time, these actions can stabilize conflicts between competing logics. This stabilization occurred from three dynamics (Initial Conflict, Conflict and Stabilization Reaction via dynamic between logic and actions) and provided a consolidation of ambidextrous capabilities in the Company (Stage 3: Stabilization via dynamics between logic and actions). From these dynamics, it is observed that, simultaneously, the actions instantiate 
new logics for the organization and previously consolidated logical reinforce (WHITTINGTON, 2006). Relationships with customers, for example, instantiate the emerging logic of focusing on new products and at the same time, strengthen the consolidated market long ago by the Beta Company. The new development process reinforces the development cycle, a focus on projects and the creativity cycle, a dedicated logic to new products.

\section{CONCLUSION}

The practice perspective allows an understanding of the ambidexterity building process from a duality between action and structure: organizational logics guide the actions of the employees in the organization. But such actions are reinforced over time, cause changes in organizational logics (WHITTINGTON, 2006).

From the results, we can point out theoretical contributions on two fronts.

First, as pointed out by Reich and Birkinshaw (2008), the literature lacks explanations on history of how different levels interact over search firms by ambidexterity. In addition, previous research approach the subject from unidirectional approaches, treating the ability of management to direct an appropriate culture to ambidexterity (O'REILLY; TUSHMAN, 2007; TUSHMAN; O'REILLY, 1996), or addressing the influences of contextual factors as causes or moderators of ambidexterity (RAISCH; BIRKINSHAW, 2008).

The approach proposed in this article, on the other hand, considers the interactions between factors at different levels (that is, logic linked to the culture of the company and actions taken on a daily routine) from a duality, considering the mutual constitution between different levels. In this sense, the three stages to build ambidexterity (Creation of initial conflicts, reaction and conflicts, stabilization via dynamics between logic and actions) contribute to an understanding of these mutual constitutions.

Second, the literature suggests ambidexterity from different strategies, the separation between use of current capacity and exploration of innovations. The structural separation and the location of these capabilities at different hierarchical levels (FLOYD; LANE, 2000) are examples. Other contributions based on contextual ambidexterity (RAISCH; BIRKINSHAW, 2008) suggest reconciling these two capacities within the same unit.

In view of this stalemate between separation and reconciliation, the results suggest that reconciliation is a prolific way for the construction of ambidexterity. This can be verified in that logical previously bound in the company were rescued to combined emerging logics, 
forming an approach that would allow the advancement of the innovative development work. As an example, we can mention outsourcing, developed to enhance the new logic of downsizing but influenced by old designs logic. Similarly, in the process of development of innovation, the logic of projects had to be restored in innovation management in order to, combined with a new logic open to experimentation (new products), create a balanced approach.

Under the managerial point of view, the work demonstrates that old logic that initially conflict with actions aimed at building ambidexterity can, along the process, be useful. The need to rescue old logic occurs even in functional separation strategies. Logics related to the use of current capabilities can be very useful, especially for the promotion of concrete progress in environments characterized by experimentation and greater fault tolerance.

This study presents, however, limitations. The conclusions are based on a single case study, so that further studies can be conducted in other contexts in order to consider different characteristics. In the case analyzed, the shift to a focus on innovation has emerged, largely by the crisis. However, as pointed out by Tushman and O'Reilly (1996), other factors such as technological changes, can also drive companies to position themselves to generate new solutions. Thus, further studies can be conducted in contexts in which the change is triggered by other factors, to ascertain similarities and differences with the results obtained in this work. Finally, the case under consideration belongs to the software industry, where production processes have essentially creative nature, even in settings marked by periods and pressures for control such as is the designs (SOMMERVILLE, 2007). Therefore, further studies can be conducted in companies in other sectors with more rigid processes such as mining, in order to verify differences in the software industry.

\section{REFERENCES}

AUH, S.; MENGUC, B. Balancing exploration and exploitation: the moderating role of competitive intensity. Journal of Business Research, v. 58, p. 1652-1661, 2005.

BATTILANA, J.; DORADO, S. Building sustainable hybrid organizations: the case of commercial microfinance organizations. Academy of Management Journal, v. 53, n. 6, p. 1419-1440, 2010.

BINDER, A. For love and money: organizations' creative responses to multiple environmental logics. Theory \& Society, v. 36, n. 6, p. 547-571, 2007.

CORBETT-ETCJEVERS, I. A narrative framework for management ideas: disclosing the plots of knowledge management in a multinational company. Management Learning, v. 42, n. 2, p. 165-181, 2011. 
EISENHARDT, K. Building theories from case study research. The Academy of Management Review, v. 14, n. 4, p. 532-550, 1989.

FELDMAN, M. S.; ORLIKOWSKI, W. No title. Organization Science, v. 22, p. 1240-1253, 2011.

FLOYD, S.; LANE, P. Strategizing throughout the organization: managing role conflict in strategic renewal. Academy of Management Review, v. 25, p. 154-177, 2000.

GIBSON, C. B.; BIRKINSHAW, J. The antecedents, consequences and mediating role of organizational ambidexterity. Academy of Management Journal, v. 47, p. 209-226, 2004.

GIDDENS, A. The construction of society: outline of the theory of structuration. Berkeley: University of California, 1984.

HE, Z.; WONG, P. K. Exploration vs. exploitation: an empirical test of the ambidexterity hypothesis. Organization Science, v. 15, n. 4, p. 481-494, 2004.

JANSEN, J. J. P.; VAN DEN BOSCH, F. A. J.; VOLBERDA, H. W. Exploratory innovation, exploitative innovation, and ambidexterity: the impact of environmental and organizational antecedents. Schmalenbach Business Review, v. 57, p. 351-363, 2005.

JARZABKOWSKI, P. Shaping strategy as a structuration process. Academy of Management Journal, v. 51, n. 4, p. 621-650, 2008.

KIRK, J.; MILLER, M. L. Reliability and validity in qualitative research. Thousand Oaks: Sage, 1986.

LAVIE, D.; KANG, J.; ROSENKOPF, L. Balance within and across domains: the performance implications of exploration and exploitation in alliances. Organization Science, v. 22, n. 6, p. 1517-1538, 2011.

LI, S.; SHANG, J.; SLAUGHTER, S. A. Why do software firms fail? Capabilities, competitive actions, and firm survival in the software industry from 1995 to 2007. Information Systems Research, v. 21, n. 3, p. 631-654, 2010.

LINCOLN, Y. S.; GUBA, E. G. Naturalistic inquiry. Newbury Park: Sage, 1985.

LOK, J.; DE ROND, M. On the plasticity of institutions: containing and restoring practice breakdowns at the Cambridge University Boat Club. Academy of Management Journal, v. 56, n. 1, p. 185-207, 2012.

LUBATKIN, M. H. et al. Ambidexterity and performance in small- to mediumsized firms: The pivotal role of top management team behavioral integration. Journal of Management, v. 32, n. 5, p. 646-672, 2006.

LYYTINEN, K.; NEWMAN, M. Explaining information systems change: a punctuated sociotechnical change model. European Journal of Information Systems, v. 17, p. 589-613, 2008 .

LYYTINEN, K.; ROSE, G. M. Disruptive information systems innovation: the case of internet computing. Information Systems Journal, v. 13, n. 4, p. 301-330, 2003. 
MALHOTRA, N. K.; BIRKS, D. F. Marketing research: an applied approach. London: Prentice Hall, 2007.

NAPIER, N. P.; MATHIASSEN, L.; ROBEYD. Building contextual ambidexterity in a software company to improve firm-level coordination. European Journal of Information Systems, v. 20, p. 674-690, 2011.

NEWELL, S. et al. Managing knowledge work and innovation. New York: Palvagre Macmillan, 2009.

O'REILLY, C. A.; TUSHMAN, M. L. Ambidexterity as a dynamic capability: resolving the innovator's dilemma. , nº 07-088. Cambridge: [s.n.], 2007.

ORLIKOWSKI, W. Sociomaterial practices: exploring technology at work. Organization Studies, v. 28, n. 9, p. 1435-1448, 2007.

RAISCH, S.; BIRKINSHAW, J. Organizational ambidexterity: antecedents, outcomes, and moderators. Journal of Management, v. 34, p. 375-409, 2008.

ROPER, S.; DU, J.; LOVE, J. H. Modelling the innovation value chain. Research Policy, v. 37, n. 6-7, p. 961-977, 2008.

SCHATZKI, T. Social practices:a wittgensteinian approach to human activity and the social. Cambridge: Cambridge University, 1996.

SIRÉN, C. A.; KOHTAMAKI, M.; KUCKERTZ, A. Exploration and exploitation strategies, profit performance, and the mediating role of strategic learning: escaping the exploration trap. Strategic Entrepreneurship Journal, v. 6, p. 18-41, 2012.

SMETS, M.; MORRIS, T.; GREENWOOD, R. From practice to field: a multilevel model of practice-driven institutional change. Academy of Management Journal, v. 55, n. 4, p. 877904, 2012.

SOMMERVILLE, I. Engenharia de software. São Paulo: Pearson, 2007.

TEECE, D. J. Profiting from technological innovation: Implications for integration, collaboration, licensing and public policy. Research Policy, v. 15, n. 6, p. 285-305, 1986.

TUSHMAN, M. L.; O'REILLY, C. A. Ambidextrous organizations: managing evolutionary and revolutionary change. California Management Review, v. 38, n. 4, p. 8-30, 1996.

VINEKAR, V; SLINKMAN, C. W.; NERURS, S. Can agile and traditional systems development approaches coexist? An ambidextrous view. Information Sytems Management, v. 23, p. 31-42, 2006.

WHITTINGTON, R. Completing the practice turn in strategy research. Organization Studies, v. 27, n. 5, p. 613-634, 2006. 